\section{Practical Considerations}

From available evidence lymphography must be considered to be a potentially dangerous method of investigation. However, if certain precautions are taken no serious complications should develop. Particular care should be taken over the amount of Lipiodol Ultra Fluid injected, especially after lymphadenectomy or in the presence of lymphatic obstruction, and the procedure should not be undertaken when there is pre-existing pulmonary disease. To prevent the occurrence of thrombo-embolism it is suggested that the limbs should rest on a soft mattress, and should periodically be passively exercised while the investigation is proceeding.

\section{Summary}

Lymphography with Lipiodol Ultra Fluid was successfully performed in 110 out of a consecutive series of 115 female patients with a carcinoma arising from the genital tract. The complications associated with the procedure were recorded. In 98 the study was bilateral and in 12 unilateral. The investigation was repeated in 20 patients; in eight this was bilateral and in 12 unilateral. The total amount of contrast medium injected in any patient did not exceed $16 \mathrm{ml}$.

Minor complications, which have been described by most other workers, developed in $30 \%$ of cases, but there has been little previous reference to two complications which occurredthrombo-embolism and haemoptysis. The occurrence of thrombo-embolism in three patients may have been precipitated by venous stasis resulting from complete immobility of the limbs over a period of three to four hours. Haemoptysis which occurred in six patients probably resulted from breakdown of oil and release of fatty acids in the lungs.

The repeat studies indicated that no permanent interference with the internodal or intranodal lymph circulation develops after lymphography.
I am grateful to Professor H. C. McLaren for his generous help and encouragement and to the staff of the Department of Obstetrics and Gynaecology for advice and technical assistance. I wish to express my thanks to Dr. C. W. Taylor (Department of Pathology, Women's Hospital), Dr. E. H. Mucklow (Department of Radiology, Women's Hospital), and Professor J. B. Kinmonth (Department of Surgery, St. Thomas's Hospital, London) for their help and criticisms. I am indebted to the Consultant Medical Staff of the Birmingham and Midland Hospital for Women for allowing me to study clinical material under their care. My thanks are also due to Sister P. Bushnell, Miss S. Reeve, and Mr. A. Betts for their willing help and cooperation. This study was partly supported by a grant from the British Empire Cancer Campaign while holding a Research Fellowship in the University of Birmingham.

\section{REFERENCES}

Bron, K. M., Baum, S., and Abrams, H. L. (1963). Radiology, 80, 194. Chiappa, S., Galli, G., and Palmia, C. (1964). Clin. Radiol., 15, 202. Desprez-Curely, J. P., Bismuth, V., and Laugier, A. (1962). Cited by Gough et al. (1964).

Fraimow, W., Wallace, S., Lewis, P., Greening, R. R., and Cathcart, R. T. (1965). Radiology, 85, 231 .

Gough, J. H., Gough, M. H., and Thomas, M. L. (1964). Brit. J. Radiol., 37, 416.

Guiney, E J., Gough, M. H., and Kinmonth, J. B. (1964). F. cardiovasc. Surg. (Torino), 5, 346.

Hamilton, R. W., Hustead, R. F., Peltier, L. F., Kuenzig, M. C., Strandmark, J. F., and Rosenbaum, S. M. (1964). Surgery, 56, 53

Howett, M., and Elmendorf, E. A. (1965). Obstet. and Gynec., 26, 34. Hreshchyshyn, M. M., and Sheehan, F. R. (1960). Proc. Amer. Ass. Cancer Res., 3, 121.

Jackson, L., Wallace, S., Schaffer, B., Gould, J., Kramer, S., and Weiss, A. J. (1961). Ann. intern. Med., 54, 870.

Jackson, R. J. A. (1966). 7. Obstet. Gynaec., Brit. Cwlth, 73, 71

Kinmonth, J. B. (1954). Ann. roy. Coll. Surg. Engl., 15, 300.

Koehler, P. R., Wohl, G. T., and Schaffer, B. (1964). Amer. F. Roentgenol., 91, 1216

Litwin, S. B., Fraley, E. E., Clouse, M. E., and Ulfelder, H. (1964). Obstet. and Gynec., 24, 809.

Schaffer, B., Koehler, P. R., Deniel, C. R., Wohl, G. T., Rivera, B., Meyers, W. A., and Skelly, J. F. (1963). Radiologv, 80, 917.

Tiernberg, B. (1962). Acta radiol. (Stockh.), Suppl. No 214

Viamonte, M., Altman, D., Parks, R., Blum, E., Bevilacqua, M., and Recher, L. (1963). Radiology, 80, 903.

Wallace, S., Jackson, L., Schaffer, B., Gould, J., Greening, R. R., Weiss, A., and Kramer, S. (1961). 'Ibid., 76, 179.
In a review of acute diverticulitis McLaren (1957) observed : "This review has revealed two surprising features in the British and American literature on perforated diverticulitis. The first is the lack of adequate statistical information regarding the incidence and mortality of this condition; the second, that there has not been any investigation of the factors determining death or survival." Surgical literature does not lack expressions of opinion on the treatment of the condition, but statistical support for opinions expressed is much less in evidence.

In the search for more reliable information on the late results of treatment in diverticulitis of the colon 100 consecutive cases operated on at the West Middlesex Hospital during 1948-57 were followed up and their subsequent progress was studied. The follow-up was conducted by questionaries to general practitioners and patients, and, where necessary, by interview. Except in nine cases, the follow-up covered a minimum period of five years or until death, the maximum period being 15 years. To eliminate clinical and radiological errors the study was confined to cases in which the diagnosis had been established at operation. In all cases subject to resection the specimen has been examined histologically to confirm the diagnosis of diverticular disease of the colon, and no cases with associated pathology, such as Crohn's disease, ulcerative colitis, or carcinoma, have been included. The first operative procedure occurring in 1948-57 was regarded as the starting-point of the study, being referred to as the "definitive attack." The cases were consecutive and unselected, but exclusion of those treated non-operatively probably produced a bias towards the more severe forms of the disease. Ages ranged from the fourth to the ninth decade, females predominated by more than 2 to 1 , and in all cases the disease was most severe in the sigmoid colon. The manner of presentation is given in Table $I$.

* West Middlesex Hospital, London.

† Department of Surgery, University of Queensland. 
The cases are discussed in five groups: (1) simple acute inflammation, (2) intestinal obstruction, (3) massive bleeding, (4) elective surgery, and (5) fistula.

TaBle I.-100 Cases of Diverticulitis Treated Surgically. Mode of Presentation

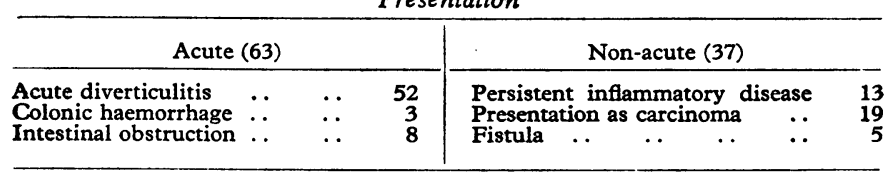

\section{Simple Acute Inflammation}

Fifty-two patients were admitted as emergency cases with acute diverticulitis and varying degrees of peritonitis, and were operated upon within 24 hours of admission. Most of them received antibiotics, usually penicillin and streptomycin or one of the tetracyclines. The methods of surgical treatment are set out in Table II and the outcome in Table III.
TABLE II.-Surgical Treatment of Acute Diverticulitis (52 Patients) Laparotomy (with or without drainage and/or suture) $\quad 33(64 \%)$ Laparotomy and colostomy
Early but not immediate resection, 7 patients.

TABLE III.-Results of Surgery in Acute Diverticulitis (52 Patients, After 5-15 Years)

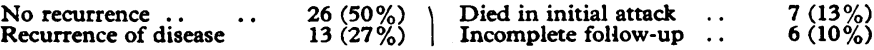

\section{Immediate Mortality}

Seven patients died during hospitalization for the definitive attack. Thre died within 12 hours of operation from gross faecal peritonitis-one treated by laparotomy only, one by transverse colostomy, and one by exteriorization of the lesion -while a fourth early death was due to bilateral adrenal haemorrhage. Two deaths occurred in patients treated by simple suture of the sigmoid perforation, without peritoneal drainage; a total of six patients were treated in this way. At post-mortem examination reperforation had taken place in both cases. The remaining death resulted from a gangrenous abscess of the sigmoid mesocolon, treated by proximal colostomy and drainage. Of the 52 cases with acute diverticulitis four had actual faecal material in the peritoneal cavity, while the remaining 48 had a purulent or seropurulent exudate. The mortality of those with faecal peritonitis was $75 \%$, compared with $8 \%$ for those without it. While simple mortality figures disregarding the degree of peritonitis present or the patient's age and cardio-respiratory state may be misleading, it is obvious that frank faecal peritonitis carries a high mortality, and that failure to drain the peritoneal cavity is a dangerous omission.

\section{Further Symptoms Due to Diverticulitis}

If early deaths, cases treated by resection, and those lost to follow-up are excluded 33 cases from this group remain for long-term assessment. Of these, $20(61 \%)$ have not needed to consult their doctors for bowel symptoms since discharge and $13(39 \%)$ have had further divertic'llitis. Five patients had attacks requiring hospitalization during the first year after the definitive attack but were subsequently free from symptoms for an average period of seven years. Five had persistent symptoms throughout the follow-up period-two mildly, one severe enough to merit resection, and two who were considered unfit for resection and became chronic invalids. Two further patients subsequently developed fistulae, vagino-colic or vesico-vagino-colic; and one patient, after being well for five years, developed faecal fistulae through her abdominal scar and died, this being the only late death from the disease in the series. Thus of 33 surviving patients not undergoing resection in the original attack, only one died from diverticulitis during the follow-up period and only five showed the inexorable course widely attributed to diverticulitis by authors advocating routine surgical resection, while two of these five were unfit for resection. Even in those patients showing persistent disease and fistulae there was a tendency to natural regression and prolonged remission. Left to itself the disease tends to "burn itself out."

\section{Comparison of Results According to Methods Used in Treatment of Acute Diverticulitis}

The late results of acute diverticulitis treated by different methods are set out in Tables IV, V, and VI. Studies of the clinical case notes of these patients show that the method used

TABLE IV.-Late Results of Simple Laparotomy for Acute Diverticulitis (26 Patients, After 5-15 Years)

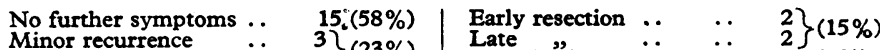

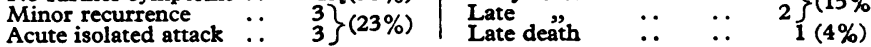

TABle V.-Late Results of Primary Colostomy in Acute Diverticulitis (16 Patients, After 5-15 Years)

\begin{tabular}{|c|c|c|c|}
\hline Final State & Total & Well & Recurrence \\
\hline $\begin{array}{l}\text { Permanent colostomy ... } \\
\text { Colostomy closed without resection : }\end{array}$ & 4 & $\begin{array}{l}2 \\
3\end{array}$ & $\begin{array}{l}2 \\
3\end{array}$ \\
\hline Incomplete follow-up $\ldots$ with $\ldots$ : & $\begin{array}{l}5 \\
1\end{array}$ & -4 & 1 \\
\hline
\end{tabular}

TABLE VI.-Late Results of Early Resection in Acuse Diverticulitis (7 Patients, After 5-15 Years)

$$
\begin{array}{lllllll}
\text { No recurrence } & \ldots & \ldots & \ldots & \ldots & \ldots & 6 \\
\text { Recurrence } & \ldots & \ldots & \ldots & \ldots & \ldots & 1
\end{array}
$$

was related to the practice of the surgeon rather than to the details of the condition found at operation. Particularly was this so regarding the use of proximal colostomy in addition to drainage. The high incidence of recurrence and the severity of the subsequent disease in cases treated by colostomy without resection is particularly conspicuous. The five most intractable cases in the series belong to this group, and as these cases show no special features in their previous histories or operative findings they suggest that the use of a colostomy without subsequent resection may be associated with an increase in morbidity compared with simple laparotomy. This conclusion applies as much to permanent colostomy as to closure of a colostomy without resection. The reliability of retrospective studies of this nature is always open to question because of the difficulty in interpreting the results of other observers. For this reason it is possible that the poorer results of cases treated by colostomy were due to selection of more severe cases for this mode of treatment, despite the above-stated association of method used with the consultant surgeon concerned.

Only one case among seven treated by early resection suffered recurrence, though this patient developed peritonitis requiring laparotomy and drainage two years after resection and has had persistent symptoms since. Simple laparotomy gave a higher recurrence rate (32\%) over a longer average follow-up, but the recurrences were usually mild or solitary episodes. Crude recurrence rates, without reference to the frequency or severity of the recurrences, tend to give a distorted picture of the morbidity caused by the disease.

\section{Assessment of Prognosis in Patients with Acute Diverticulitis}

Resection of the primary lesion has been shown to improve the long-term prognosis in acute diverticulitis, but it is also 
apparent that many cases carry a good prognosis without it. To avoid unnecessary surgical risk it is important to identify, at as early a stage as possible, those patients likely to have further serious trouble. Analysis of the present series suggests that two considerations may help this identification.

1. Previous History.-Of the 52 acute cases in the series 10 had symptoms of diverticulitis for weeks or months before the definitive attack. These 10 patients fared rather worse than the group as a whole, only three surviving symptom-free after conservative operations. Of the 42 without important symptoms before the acute attack 10 had furthed disease, but of notably less severity than those with longer histories. Previous history, particularly if symptoms are persistent, appears to be associated with increased subsequent morbidity, but recurrent isolated attacks, with long free periods between, carry no worse prognosis in later than in earlier attacks.

2. Pathological State at Operation.-Study of operation notes suggests a definite tendency for a large inflammatory mass to be associated with a worse prognosis, as might be expected. However, as such a mass, believed to be malignant, may have disappeared completely at a second laparotomy a few weeks after the first, it is obvious that this conclusion is not always valid in an individual case.

\section{Acute Intestinal Obstruction}

Eight cases in the series presented with acute intestinal obstruction, the obstruction being predominantly smallintestinal in three cases and colonic in five. Small-bowel obstruction was due to adhesion of the ileum to a sigmoid inflammatory mass in each case, and two of the patients died after operation. The third, treated by ileo-transverse anastomosis, survived without symptoms until death from an unrelated cause. In four of the cases of colonic obstruction the condition was produced by a sigmoid inflammatory mass, and only the fifth patient displayed true fibrous stricture of the colon. The four patients with inflammatory masses gave no history of previous colonic disease, but the patient with a fibrous stricture had undergone laparotomy for diverticulitis two years before. One patient, considered unsuitable for resection, died of a pulmonary embolus, and two were resected and have been symptomless for 6 and 13 years respectively. Of two who were given permanent colostomies one remained well until lost to follow-up three years later, while the other developed major recurrent diverticular disease after six years of good health.

\section{Massive Bleeding}

Though many patients in this series have complained of rectal bleeding during their illness, only three required surgery on this account. One bled persistently for a month and then had an acute inflammatory mass resected; the second, with massive bleeding, was found to have a pericolic abscess and underwent a three-stage resection; the third had a diagnostic laparotomy after severe bleeding and was found to have a segment of acute diverticulitis which was not resected. None of these patients had recurrence of diverticular disease during follow-up. The findings in these three cases contrast sharply with the usual experience that severe bleeding occurs in association with uninflamed diverticula.

\section{Uncomplicated Interval Surgery}

Thirty-seven cases underwent interval operations for diverticular disease. Five of these had fistulae and are discussed separately; the late results of the remaining 32 are set out in Table VII. Nineteen cases underwent laparotomy to exclude carcinoma, and all but two of these had no previous symptoms of diverticulitis. Thirteen patients were operated upon specifically to eradicate known diverticulitis, and all but two of these had histories of recurrent or persistent symptoms for periods of 3 to 10 years. These two groups are therefore in marked contrast with respect to a prior history of diverticulitis.

TABLE VII.-Late Results of Interval Operation for Diverticulitis (32

\begin{tabular}{|c|c|c|c|c|c|}
\hline & & Total & $\begin{array}{c}\text { No Recur- } \\
\text { rence }\end{array}$ & $\begin{array}{c}\text { Recur- } \\
\text { rence }\end{array}$ & $\begin{array}{l}\text { Follow-up } \\
\text { Incomplote }\end{array}$ \\
\hline $\begin{array}{l}\text { Resection .. } \\
\text { Simple laparotomy } \\
\text { Colostomy - closed without } \\
\text { Permanent colostomy }\end{array}$ & \begin{tabular}{lr}
$\cdots$ & $\cdots$ \\
\hdashline & $\cdots$ \\
resection \\
$\cdots$ & $\cdots$
\end{tabular} & $\begin{array}{r}20 \\
9 \\
2 \\
1\end{array}$ & $\begin{array}{r}17 \\
5 \\
-\end{array}$ & $\begin{array}{l}1 \\
4 \\
2 \\
1\end{array}$ & 三 \\
\hline
\end{tabular}

Operation to Exclude Carcinoma (19 Patients).-Twelve of these had a sigmoid colectomy : two were lost to follow-up, nine remained free of major symptoms for an average of seven and a half years, and one had a single acute episode six years after resection, recovering on conservative treatment. Five cases were treated by laparotomy only (three because the condition found was slight and two because it was too severe for safe resection). One of these cases had a single attack of diverticulitis six years post-operatively and recovered fully, while four had no further symptoms during an average period of 10 years. The remaining two cases in this group had large diverticular masses and were given colostomies, which were closed subsequently without resection. Both of these patients had further trouble with recurrence of gross inflammatory disease. In this group of patients with symptoms of short duration simple laparotomy or resection gave comparable satisfactory results.

Operation for Known Diverticulitis (13 Patients).--Eight patients underwent resection of their diverticulitis and have remained symptom-free throughout the follow-up. In five resection was regarded as too hazardous, and three of these had further severe symptoms-two for several years, with subsequent prolonged freedom, the other until resection 10 years after the original laparotomy. In this group of patients with long histories the results of resection are most gratifying and evidently superior to less radical measures, but it is noticeable that after varying periods of activity the diverticulitis not undergoing resection has generally tended to burn itself out.

\section{Fistula}

Apart from fistulae of the abdominal wall after drainage of acute diverticulitis there were seven patients with major fistulae, vesico-colic or vagino-colic, or both, and the details are set out in Table VIII. In five patients, all women, the appearance of a fistula was the symptom which first brought them to hospital, while one had no antecedent bowel symptoms of any kind. Two patients treated by three-stage resections were symptom-free after seven and eight years respectively, but a third died post-operatively. In one patient treated by simple closure the fistula recurred and persisted for several years. The patient treated by colostomy alone-the fistula recurred when the colostomy was closed-has subsequently been lost to follow-up. Two patients developed fistulae after operations for acute diverticulitis and refused further surgery. Both had symptoms for several years; then healing occurred spontaneously, and they have remained healed for two and seven years respectively.

Table VIII.-Fistula in Diverticulitis (7 Patients)

\begin{tabular}{|c|c|c|c|c|c|}
\hline \multicolumn{3}{|c|}{ Treatment } & Total & Recurrence & No Recurrence \\
\hline $\begin{array}{l}\text { Resection } \\
\text { Simple closure .. } \\
\text { Colostomy-closed } \\
\text { Refused surgery }\end{array}$ & $\begin{array}{c}\text { without } \\
\text {.. }\end{array}$ & $\begin{array}{l}\because \\
\ddot{\text { resection }} \\
\cdots\end{array}$ & $\begin{array}{l}3 \\
1 \\
1 \\
2\end{array}$ & $\begin{array}{c}\text { (1 death) } \\
1 \\
1 \\
-\end{array}$ & $\frac{2}{2}$ \\
\hline
\end{tabular}




\section{Resection for Diverticulitis}

In the whole series 36 patients underwent resections for diverticulitis-34 during the definitive attack and two eight and 10 years later. The results are summarized in Table IX. One died, giving a mortality of $2.8 \%$, and two $(5.6 \%)$ had recurrent major disease during an average follow-up of seven years. In each recurrence a single attack of acute diverticulitis required hospitalization, and, in one, laparotomy and drainage. After resection 10 patients (28\%) complained of mild diarrhoea and abdominal pain two or three times a year. It can be seen, therefore, that satisfactory results may not be obtained if resection is advised for symptoms of this degree of severity. The average length of colon resected was $15 \mathrm{~cm}$. in the preserved specimen $(22 \mathrm{~cm}$. in vivo), suggesting that most cases do not need extensive resection.

TABLE IX-Results of Resection for Diverticulitis (36 Patients, After Symptom-free Major recurrence$$
\text { 5-15 Years) }
$$$$
21(59 \%) \text { Operative death }
$$$$
\begin{aligned}
2(5 \cdot 6 \%) \\
10(28 \%)
\end{aligned}
$$

Incomplete follow-up $1(2.8 \%)$

Minor

$10(28 \%)$

\section{Discussion}

Knowledge of the natural history of diverticulitis and of its prognosis with various types of management is notably inadequate. Since the early contributions of Telling and Gruner (1916-17), Spriggs and Marxer (1927), and Edwards (1939) an extensive literature has grown up on the subject, but it has lacked an adequate statistical basis for the opinions expressed. Laufman et al. (1962) list 268 references on the subject, but only six of these give useful follow-up statistics. Recently increasing interest has been shown in the fundamental pathology and physiology of the sigmoid colon (Morson, 1963 ; Ritchie et al., 1962), but this trend needs to be supported by more critical surveys of the problems of managing diverticulitis. The general tendency is to stress the severe progressive forms of the disease and to ignore the commoner picture of single or widely spaced attacks. This concept of the disease encourages routine resection-threestage (Beard and Gazet, 1961), interval (Starkloff and Lewis, 1956), or emergency (Ryan, 1958; Madden and Tan, 1961). Proof that resection carries a lower mortality and morbidity than does the untreated disease is at present less than adequate. A brief review of the findings of writers interested in the long-term course of diverticulitis may be helpful.

Horner (1958) followed 503 cases diagnosed radiologically and found that the incidence of inflammatory complications was $9.7 \%$ after five years but $36.7 \%$ at 11 to 18 years. However, in the great majority a simple attack of acute inflammation responded to medical treatment and only two cases in the whole series required surgery. Boles and Jordan (1958) reviewed 294 cases with diverticula, followed up for 10 to 30 years : $40 \%$ had complications, usually simple acute inflammation occurring early in the disease and with little tendency to recurrence; only $6 \%$ had more than two attacks; and 16 patients in the whole series required surgery. The smaller series of McCollum (1959) gives similar results. Greene (1957) reported a different experience in which two-thirds of the patients with colonic diverticula had recurrent disease during a follow-up of one to twenty years, but gave no details of the severity of the inflammatory attacks.

Follow-up studies of diverticulitis treated surgically are often uninformative or misleading. Ryan (1958) quoted LockhartMummery (1938) as stating that survivors of resection were cured. In fact Lockhart-Mummery stated that the patients " did well ; several of them were followed up for a number of years." Other reports of ten referred to are those of Smithwick (1942) and Boyden (1950), but these are equally unsatisfactory in providing information on long-term results. Two reports with a more adequate follow-up come from the Mayo Clinic. In the series of Waugh and Walt (1962) 7 (11\%) patients out of 65 who had had resections had severe recurrence within five years, while Leigh et al. (1962) reported that of 72 patients who had non-inflamed diverticula after resection $16 \%$ had some degree of recurrence during a five-year follow-up. Other clinics also report significant recurrence rates after resection: Romsdahl and Cole (1963), 25\% ; Rodkey and Welch (1959), $5 \%$ requiring further surgery; and Pemberton et al. (1947), who found $22 \%$ recurrence. The patienis in the present series who underwent rerection had a $6 \%$ recurrence rate, while $33 \%$ had continuing minor symptoms.

Mortality figures for resection in diverticulitis range from none in 150 cases by Colcock (1963), through $2.7 \%$ by Rodkey and Welsh (1959), to $7.5 \%$ by Romsdahl and Cole (1963). These figures were all from centres with a special interest in colonic surgery. The mortality in general hospitals might well be higher, and Hartley (1964) supports this view. Viewed in relation to severe progressive diverticulitis, mortality and recurrence figures may be acceptable, but they cannot be said to justify resection after a single acute attack of diverticulitis.

\section{Place of Prophylactic Resection}

The critical issue in the management of diverticulitis is whether surgery in early cases is justified by the immediate and long-term results and whether the late mortality and morbidity are likely to be reduced by more resections early in the course of the disease, as is frequently advocated. All will agree that the severe progressive cases should have surgery, even though they tend to burn themselves out after three to four years. It is clearly unreasonable to condemn patients to such a period of pain, or the discomfort of fistula, when relief can be provided. Though there has been only one late death in the series this low mortality is probably fortuitous. The choice between resection and conservative surgery is most difficult in acute peridiverticulitis and perforation, the form of the disease that most commonly confronts the surgeon.

In the present series cases followed up after conservative surgery for acute diverticulitis have been completely symptomfree in $64 \%$, and $36 \%$ have had further trouble. This $36 \%$ is made up of $6 \%$ with mild symptoms, $15 \%$ with one or two attacks shortly after the first one, followed by freedom from symptoms for an average of seven years, and $15 \%$ with severe disease. As one-third of the patients treated by resection had mild symptoms similar to those in the group not resected, and isolated acute attacks of diverticulitis are the usual form of recurrence after resection, the results in the resected and unresected groups are very similar apart from the $15 \%$ with severe symptoms. Of the $15 \%$ who had severe recurrence half were regarded as unsuitable for resection because of the severity of the disease or associated medical conditions. If routine early resection had been performed for acute perforated diverticulitis throughout the series 11 unnecessary resections would have been carried out for every beneficial one, judged by the progress of the cases over an average period of seven years.

This study suggests that resection should be reserved for cases with proved persistent disease, except in those where resection is obligatory because malignancy cannot be excluded. Late morbidity appears to be associated with a history of persistent symptoms of diverticulitis lasting some months, but not with recurrent acute episodes if the patient is symptom-free between attacks. An unfavourable prognosis is further suggested by the presence of an advanced pathological condition, as shown by a large fixed mass. These criteria for selecting cases for resection may result in operating on patients with severe disease rather than at an early stage of the disease process, but will avoid many unnecessary resec- 
tions. Furthermore, routine early resection is unlikely to decrease greatly the number of cases with advanced disease coming to operation, for a large proportion of these cases have previously had no significant symptoms (Dawson et al., 1965). Many cases first present with advanced disease, while many with mild conditions never become "advanced."

\section{Place of Colostomy in Treating Diverticulitis}

It is now generally accepted that proximal colostomy, temporary or permanent, is ineffective in the treatment of diverticular disease unless followed by resection. Pemberton et al. (1947) reported that $30 \%$ of the cases treated by a permanent colostomy were not controlled and that $70 \%$ of those whose colostomies were closed without resection had serious recurrent disease. Lloyd-Davies (1953) recorded similar experiences. These authors did not report control series treated by laparotomy only, but in the present series simple laparotomy gave a recurrence rate of $38 \%$ compared with $50 \%$ in patients treated by permanent colostomy and $50 \%$ in patients whose colostomies were closed without resection. Moreover, the most intractable cases were particularly prominent in the group undergoing colostomy without resection. These observations suggest the possibility that colostomy is not only ineffective but, by diverting the faecal stream and allowing contraction of the affected bowel, interferes with drainage of the diverticulum and favours inflammatory complications. That the prolonged use of proximal colostomy does indeed increase the severity of the disease process cannot be deduced with certainty from this series, as the numbers are too small, and the fallacies associated with retrospective studies must be taken into consideration. However, it is hoped that other workers may be stimulated to investigate this aspect of the management of diverticulitis.

\section{Summary and Conclusions}

One hundred consecutive cases of sigmoid diverticulitis, confirmed by laparotomy, have been followed up for 5 to 15 years in an attempt to clarify the natural course of the disease and the influence of operative procedures on its progress.
The course appears to be more benign than is often suggested, with a strong tendency to natural regression. A few patients experience prolonged and severe morbidity and will merit resection. The study suggests that extension of the scope of resection to include frequent emergency or threestage resection for patients with acute diverticulitis is not justified.

Our thanks are due to Mr. W. J. Ferguson and Mr. J. Scholefield for allowing us to study cases treated by members of their units during 1948-57. We would also like to thank Mr. Harold Edwardo, who read an earlier draft of this paper and made many valuable suggestions and criticisms. We are grateful to many colleagues in general practice and on the staff of other hospitals who answered questionaries and provided information on the subsequent history of the patients' studied and to the many patients who answered our letters or came to hospital to see us.

\section{REPERENCES}

Beard, R. G., and Gazet, J. C. (1961). Guy's Hosp. Rep., 110, 263.

Boles, R. S., and Jordan, S. M. (1958). Gastroenterology, 35, 579.

Boyden, A. M. (1950). Ann. Surg., 132, 94.

Colcock, B. P. (1963). Postgrad. Med., 33, 217.

Colcock, B. P. (1963). Postgrad. Med., 33, 217. (1965). Brit. f. Surg., $52,354$.

Edwards, H. C. (1939). Diverticula and Diverticulitis of the Intestine. Wright, Bristol.

Greene, W. W. (1957). Amer. F. Surg., 94, 282.

Hartley, R. C. (1964). Brit. Ұ. Surg., 51, 45.

Horner, J. L. (1958). Amer. F. dig. Dis., 3, 343.

Laufman, H., Silberman, W. W., and Poticha, S. M. (1962). Int. Abstr.

Surg., 115, 409.
Leigh, J. E., Judd, E. S., and Waugh, J. M. (1962). Amer. Y. Surg., 1e3, 51 .

Lloyd-Davies, O. V. (1953). Proc. roy. Soc. Med., 46, 407.

Lockhart-Mummery, J. P. (1938). Lancet, 2, 1401

McCollum, J. K. (1959). Brit. med. Y., 2, 34.

McLaren, I. F. (1957). F. roy. Coll. Surg. Edinb., 3, 129

Madden, J. L., and Tan, P. Y. (1961). Surg. Gynec. Obstet., 113, 646.

Morson, B. C. (1963). Brit. f. Radiol., 36, 385.

Pemberton, J. de J., Black,"B. M., and Maino, C. R. (1947). Surg. Gynec. Obstet., 85,523 .

Ritchie, J. A., Ardran, G. M., and Truelove, S. C. (1962). Gastroentere$\log y, 43,642$.

Rodkey, G. V., and Welch, C. E. (1959). In Diseases of the Colon and Anorectum, edited by R. Turell, p. 633. Saunders, Philadelphia.

Romsdahl, M. M., and Cole, W. H. (1963). Arch. Surg., 86, 751.

Ryan, P. (1958). Brit. F. Surg., 45, 611.

Smithwick, R. H. (1942). Ann. Surg., 115.969.

Spriggs, E. I., and Marxer, O. A. (1927). Lancet, 1, 1067.

Starkloff, G. B., and Lewis, J. E. (1956). Amer. Surg., 22, 295.

Telling, W. H. M and Gruner O. C. (1916-17). Brit. 7. Surg, $4,468$.

Waugh, J. M., and Walt, A. J. (1962). Surg. Clin. N. Amer., 42, 1267. * Cancer Research Department, Royal Beatson Memorial Hospital, Glas-
gow. Full-time grantee of the British Empire Cancer Campaign for
Research.
t Department of Gynaecology, Vale of Leven Hospital, Dunbartonshire.
† Radiotherapy Department, Royal Beatson Memorial Hospital, Glasgow. size range below $300 \mu^{3}$. The presence of a second population was found in all the 41 cases of invasive squamous-cell carcinoma of the cervix, and out of 81 normal cases only $11 \%$ were false-positive. These results seemed so promising that we decided to test the method, and this paper describes the results.

\section{Material and Methods}

The cervical washings were obtained by aspirating $7 \mathrm{ml}$. of a $0.3 \mathrm{M}$ autoclaved solution of sodium salt of isethionic acid into a 10-ml. syringe, furnished with a 4-in. (10-cm.) No. 16 needle. The end of this was placed approximately 1 in. (2.5 